\title{
Alginate/hydrophobic HPMC (60M) particulate systems: New matrix for site-specific and controlled drug delivery
}

\author{
Kajal Ghosal", Sarbani Dey Ray
}

\author{
Dr. B. C. Roy College of Pharmacy and Allied Health Sciences, Durgapur, India, \\ Department of Pharmaceutical Technology, Jadavpur University, India
}

\begin{abstract}
This study aimed to obtain site-specific and controlled drug release particulate systems. Some particulates were prepared using different concentrations of sodium alginate ( $\mathrm{Na}-\mathrm{Alg}$ ) alone and others were formulated using different proportions of Na-Alg with hydroxypropyl methylcellulose (HPMC) stearoxy ether (60M viscosity grade), a hydrophobic form of conventional HPMC, using diclofenac potassium (DP) by ion-exchange methods. Beads were characterized by encapsulation efficiency, release profile, swelling, and erosion rate. The suitability of common empirical (zero-order, first-order and Higuchi) and semi-empirical (Ritger-Peppas and Peppas-Sahlin) models was studied to describe the drug release profile. The Weibull model was also studied. Models were tested by non-linear least-square curve fitting. A general purpose mathematical software (MATLAB) was used as an analysis tool. In addition, instead of the widely used linear fitting of log-transformed data, direct fitting was used to avoid any sort of truncation or transformation errors. The release kinetics of the beads indicated a purely relaxation-controlled delivery, referred to as case II transport. Weibull distribution showed a close fit. The release of DP from Na-Alg particulates was complete in 5-6 hours, whereas from Na-Alg hydrophobic HPMC particulate systems, release was sustained up to 10 hours. Hydrophobic HPMC with Na-Alg is an excellent matrix to formulate site-specific and controlled drug release particulate systems.
\end{abstract}

Uniterms: Drugs/release particulate systems. Drugs/release profile. Hydroxypropyl methylcellulose stearoxy ether. Sodium alginate. Direct fitting. Case II transport. Beads/characterization. Beads/release kinetics.

Este estudo teve como objetivo a obtenção de sistemas particulados para a liberação controlada de fármacos em sítios de ação específicos. Algumas partículas foram preparadas utilizando-se diferentes concentrações de alginato de sódio (Na-Alg) e outras foram formuladas por diferentes proporções de Na-Alg com estearoxílico éter de hidroxipropilmetilcelulose (HPMC) (grau de viscosidade 60M), uma forma hidrofóbica do convencional HPMC, utilizando o diclofenaco de potássio (DP) por métodos de troca iônica. Os grânulos foram caracterizados pela eficiência de encapsulação, perfil de liberação, inchaço e taxa de erosão. A adequação de diferentes modelos empíricos (de ordem zero, primeira ordem e Higuchi) e semi-empíricos (Ritger-Peppas e Peppas-Sahlin) foi estudada para descrever o perfil de liberação do fármaco. O modelo de Weibull também foi estudado. Os modelos foram testados através de ajuste não linear de curva pelo método dos mínimos quadrados. O software matemático MATLAB foi utilizado como ferramenta de análise matemática. Além disso, em vez do método de ajuste linear de dados transformados, foi utilizado o ajuste direto para evitar qualquer tipo de erro de truncamento ou de transformação. A cinética de liberação dos grânulos indicou liberação controlada puramente pelo processo de relaxamento, referida como transporte caso II. A distribuição de Weibull apresentou bom ajuste. A liberação do DP a partir de partículas de Na-Alg foi concluída em 5-6 horas, enquanto que a partir de sistemas particulados de Na-Alg HPMC hidrofóbico, a liberação foi mantida por até 10 horas. O HPMC hidrofóbico com Na-Alg é uma excelente matriz para a formulação de sistemas particulados para a liberação controlada de fármacos em sítios de ação específicos.

Unitermos: Fármacos/sistemas particulados para a liberação controlada. Fármacos/perfil de liberação. Éter esteroxílico de hidroxipropilmetilcelulose. Alginato de sódio. Ajuste direto. Transporte caso II. Grânulos/ caracterização. Grânulos/cinética de liberação.

\footnotetext{
"Correspondence: Kajal Ghosal. Department of Pharmaceutical Technology, Jadavpur University, Raja S. C. Mullick Road, Kolkata - 700 032, West Bengal

- India. E-mail: kaju_3_ju@rediffmail.com
} 


\section{INTRODUCTION}

The use of biodegradable polysaccharides has gained wide acceptance in the development of controlled drug delivery systems. Over the past few decades, natural biodegradable polysaccharides such as pectin, guar gum, chitosan, carrageenans, sodium alginate ( $\mathrm{Na}$-alginate), hydroxypropyl methylcellulose (HPMC), agar and gellan gum have been widely used (Kulkarni et al. 2001; Sriamornsak, et al. 2004). These polymers can be exploited in various ways in the formulation of targeted and controlled drug delivery as they have different derivatizable groups, a wide range of molecular weight, and varying chemical composition. These polymers are also called smart materials. They can change their volume in contact with external media and form a viscous layer which serves as a protective barrier against water influx and drug efflux in solution (Sinha, Rohera 2002). Thus, immediate drug release is prevented, and a sustained drug release rate can be achieved. A number of studies have investigated the use of hydrogel beads as a multiparticulate system for site-specific and controlled drug delivery. Hydrogel beads have many advantages over single-unit systems, such as uniform dispersion in the gastrointestinal (GI) tract, more uniform drug absorption, less inter- and intra-individual variability, and most importantly, targeted and controlled drug delivery. The methods for bead preparation are easily performed and reproducible. The polymers and carriers used in the preparation are nontoxic, readily available, and relatively non-expensive. Among various polymers, Na-alginate (Acikgoz et al. 1995; Gursoy, Cevic 2000; Belyaeva et al.2005) stands as the polymer of choice for bead preparation. It is a natural bioerodible polyacid and the only polymer (Gacesa 1988; Smidsrd, Skjak-Bræk 1990; Shu, Zhu 2002) that has a unique property of gel formation in the presence of multivalent cations, such as calcium ions and aluminum ions in aqueous media, which takes place mainly at junctions in the G-G sequence rich chain region known as the 'egg box junctions'. Bead formation is obtained by incorporation of the drug into a gel dispersion system, and the hydrophilic colloids (Gonzalez-Rodriguez et al. 2002) then interact with polyvalent metal ions to form insoluble colloidal complexes (calcium alginate), droplets that will precipitate in bead form. This system is generally formed by ionotropic cross-linking of natural biodegradable polysaccharides, but the resulting calcium alginate bead is usually very permeable, making it very difficult to control drug release for a prolonged period of time (Lin, Ayres 1992; Østberg et al. 1994; Ferreira, Almeida 2004). This problem can be minimized by mixing alginate with other polymers such as pectin, chitosan, ethylcellulose, and Eudragit巴. This is a useful combination due to modifications made to the original formulation of highly permeable calcium alginate beads. Conventional hydrophilic HPMC is a very useful polymer in the preparation of controlled drug delivery formulations (Das, Ahmed 2007; Ganesh et al. 2008). A hydrophobic form of HPMC is currently available and has been modified from conventional HPMC by inserting a long-chain alkyl group. Various hydrophobic groups are generally inserted into the conventional polymer backbone to modify drug release for improved therapeutic activity, and this hydrophobicity will certainly modify drug release. In our recent paper, we have shown the ability of a modified hydrophobic HPMC polymer (Ghosal et al. 2010) to form a high-viscosity hydrogel using a very small amount of material. In our present study, we extend the investigation by using this newly modified polymer in combination with $\mathrm{Na}$-alginate to form beads and to check the sustainability of the therapeutic effect obtained from this new matrix. Generally, alginate beads start to dissolve above (Sabnis et al. 1997) pH 7; thus, drug release will bypass the gastric environment, and direct contact of the drug with the gastric mucosa is prevented. Diclofenac potassium (DP) was chosen as a model drug. DP, a nonsteroidal anti-inflammatory drug (NSAID), is widely used because of its strong analgesic, antipyretic and anti-inflammatory effects (Escribanoa et al. 2003; Sintov, Botner 2006; Sanna et al. 2009). DP is available on the market as injections, oral sustained-release tablets, and topical formulations. Although DP has been shown to be one of the best tolerated NSAIDs, gastropathy occurs following oral administration, and because of its short biological half-life (1-2 hours), the drug has to be administered frequently. DP is poorly soluble (Lin, Kao 1991; Fernandez-Hervas et al. 1998) in water and acidic $\mathrm{pH}$, but rapidly soluble in alkaline $\mathrm{pH}$. Thus, an attempt was made to formulate hydrogel beads containing alginate and hydrophobic HPMC (60M) in different ratios for controlled release in alkaline $\mathrm{pH}$, which would eliminate the need for multiple dosing, thereby increasing patient compliance and decreasing the occurrence of adverse effects in the stomach. Release characteristics in different pH ranges, entrapment efficiency, polymer morphology, swelling capacity and erosion were investigated.

In this study, we compared these modified beads with bead formulations of alginate alone. Additionally, we aimed to perform some of the theoretical approaches describing drug release through the matrix. The drug is often released via molecular diffusion through the porous structure within the polymer network. For alginate beads, the matrix undergoes a combination of swelling with erosion and rapid destruction. However, if hydrophobic 
HPMC is added, drug release may be mainly dominated by swelling, with very slow erosion and destruction of the polymer. Thus, a retarded drug release can be expected. For this purpose, we examined whether these two types of beads would show a Fickian type or anomalous diffusion type of release profile by applying the Ritger-Peppas equation, which helps to get a release exponent that characterizes the mechanism of drug release. An extension of the power-law model was also applied to obtain the fraction of drug released by diffusion alone (Peppas, Sahlin 1989). This equation provides information on the relative contributions of drug diffusion and polymer relaxation to overall drug release. The equations most commonly used for in vitro data analysis are the Higuchi equation and zero-order kinetics. Residuals were plotted against time to obtain further insight into the data to assess the goodness of fit of the models. The Weibull distribution model was also included. This model alone cannot describe the kinetic properties of the drug, but it can describe the curve in terms of shape parameter (Leticia et al. 2004). Linear transformation methods were deliberately avoided, because in these methods, values are calculated mainly from log-transformed data, instead of original data, and approximation errors may accumulate over time, thereby interfering with the analysis.

\section{MATERIAL AND METHODS}

The following materials were obtained from the indicated suppliers and used as received: DP (IP grade) was kindly donated by M/S Kontest Chemicals, Kolkata, India. Hydrophobic HPMC or HPMC stearoxy ether (60 M viscosity grade) was kindly donated by Daido Chemical Corporation, Tokyo, Japan. Na-alginate (low viscosity; viscosity of $2 \%$ solution at $25^{\circ} \mathrm{C}, 250 \mathrm{cps}$ ), calcium chloride hexahydrate, anhydrous disodium hydrogen phosphate, and potassium dihydrogen phosphate were purchased from Merck, India. Other chemical reagents were obtained at the highest purity level available from the manufacturers.

\section{Methods}

\section{Analytical method}

About $100 \mathrm{mg}$ of DP was accurately weighed, transferred into a $100-\mathrm{mL}$ volumetric flask and dissolved in methanol; $10 \mathrm{~mL}$ of this solution was then transferred into a 100-mL volumetric flask. Different primary standards were prepared to generate a calibration curve, which was obtained by measuring their absorbance at $275 \mathrm{~nm}$ with an ultraviolet-visible (UV-vis) spectrophotometer. DP concentration was calculated using the linear regression equation of the calibration curve. When a standard drug solution $(2 \mu \mathrm{g} / \mathrm{mL})$ was assayed repeatedly $(\mathrm{n}=6)$, mean standard error (accuracy) and residual standard deviation (precision) were found to be $0.4 \%$ and $0.6 \%$, respectively.

\section{Preparation of beads}

DP $(2.0 \% \mathrm{w} / \mathrm{v})$ was added to aqueous solutions of varying proportions of $\mathrm{Na}$-alginate and hydrophobic HPMC and stirred until complete dissolution. This solution was dropped using a hypodermic syringe $(20 \mathrm{G})$ into a second solution, containing a saturated solution of calcium chloride $(3 \% \mathrm{w} / \mathrm{v})$. Microspheres were formed immediately and left in the original solution for $30 \mathrm{~min}$ to ensure internal gelification. The microspheres were then filtered, washed and dried at room temperature. The whole preparation process was carried out at room temperature. Table I shows bead composition.

\section{Characterization of diclofenac potassium-loaded alginate and modified hydrophobic HPMC alginate- based hydrogel beads}

\section{- Particle size determination}

After drying at $37^{\circ} \mathrm{C}$ for 48 hours, a sieving method using USP standard sieves (Jain et al. 2007) was used to measure the mean diameter of the dried beads. Shape parameters (such as area, perimeter, shape factor, and equivalent circular diameter) were calculated to characterize DP beads (Gonzalez-Rodriguez et al., 2002). The equivalent circular diameter (ECD) was calculated as follows:

$$
\mathrm{ECD}=2 \sqrt{ } \mathrm{A} / \pi
$$

where A is the area of the closed boundary of the particle. Shape factor is used to measure object complexity, namely contour complexity. The greater the variation of the contour, the higher the shape factor parameter. The value of shape factor (s) is determined as follows:

$$
\mathrm{S}=\mathrm{L}^{2} / 4 \pi \mathrm{A}
$$

where $\mathrm{L}$ is the perimeter and $\mathrm{A}$ is the area of the closed boundary of the particle.

\section{- Entrapment efficiency}

Specific amounts of beads were placed in a glass mortar. The beads were crushed into fine powder and dissolved in $1 \mathrm{M}$ sodium hydroxide solution for 24 hours in a graduated flask. The solution was filtered through a G2 filter. The clear liquid was assayed for drug content 
of beads by UV-vis spectrophotometry at $275 \mathrm{~nm}$. This is the actual amount of drug entrapped in the beads. Entrapment efficiency (EE) was calculated using the following formula:

$$
\mathrm{EE}=\mathrm{b} \times 100 / \mathrm{a}
$$

$\mathrm{b}=$ actual amount of drug present in bead.

$\mathrm{a}=$ theoretical amount of drug in bead.

\section{- Swelling capacity}

Beads were placed in a watch glass, and distilled water was added. Initial bead weight $\left(\mathrm{W}_{0}\right)$ and bead weight at different time points $\left(\mathrm{W}_{\mathrm{t}}\right)$ were measured. The swelling capacity of the individual beads was estimated as the ratio of weight at different time points to initial bead weight $\left(\mathrm{W}_{\mathrm{t}} / \mathrm{W}_{0}\right)$. The beads were handled carefully to avoid losses. Diameters were measured by the sieving method using USP standard sieves (Ebube et al., 1997). Each experiment was done in triplicate.

$$
\% \text { swelling capacity }=\left(w_{t}-w_{o}\right) \times 100 / w_{0}
$$

\section{- $\quad$ Erosion studies}

The dried beads were weighed and placed in a dissolution basket (Srinatha et al., 2008; Rao et al., 1988; Yotsuyanagi et al., 1991), followed by dissolution in phosphate buffer ( $\mathrm{pH} 7.4$ ) at $50 \mathrm{rpm}$. After a 1-hour interval, the beads were removed from the basket and oven-dried at $50{ }^{\circ} \mathrm{C}$. The water was removed, and the beads were weighed. The beads were then placed back in the basket. This process lasted 10 hours. Erosion study was performed using the following formula:

$$
\% \text { weight loss }=\left(w_{0}-w_{1}\right) \times 100 / w_{0}
$$

$w_{o}=$ Initial bead weight, $w_{1}=$ weight after drying.

\section{-Release tests (Lin, Ayres 1992):}

Drug release profiles of DP-containing formulations with an accurately weighed amount of beads were obtained using USP dissolution apparatus II (Shimadzu 1202 UV VIS-spectrophotometer). The study conditions were: a stirring speed of $50 \mathrm{rpm}$ and $900 \mathrm{~mL}$ of dissolution medium at $37 \pm 0.2{ }^{\circ} \mathrm{C}$. The simulation of GI transit conditions was achieved by changing the $\mathrm{pH}$ of the dissolution medium at different time intervals. For the first 2 hours, $\mathrm{pH}$ of the dissolution medium was buffered at $\mathrm{pH} 1.2(\mathrm{HCl} /$ $\mathrm{NaCl}$, to mimic the gastric district). The $\mathrm{pH}$ was then raised to 6.4 (phosphate buffer) and maintained at this value for another 2 hours. Finally, a slightly higher $\mathrm{pH}$ (7.4) was used up to 6 hours. At predetermined intervals, a 3-mL aliquot was withdrawn and replaced with fresh dissolution medium. The withdrawn samples were filtered and analyzed spectrophotometrically at $275 \mathrm{~nm}$. All samples were measured in triplicate, and the results were expressed as the percentage of drug released.

\section{- Release kinetics study}

DP release from beads was studied by various mathematical models. These models were applied taking into account the amount of drug released from 1 to 10 hours at different intervals as determined in release studies in vitro.

Zero-order linear equation, Higuchi square root of time equation and Weibull model were used to describe the kinetics of drug release from different formulations, and Ritger-Peppas' power-law equation and Peppas-Sahlin's weighted sum of non-linear time function (semi-empirical kinetic equations) were used only for the first $60 \%$ of drug released to denote the type of diffusion and fraction of drug release due to Fickian diffusion, respectively. All model-fitting analyses were performed by non-linear direct fitting through minimization of the sum of squared residuals (SSR). A general purpose mathematical software $\left(\right.$ MATLAB $^{\mathrm{TM}}$ ) was used as an analysis tool.

Three equations employed in this study, zero-order model, Higuchi square root equation and Ritger-Peppas model, are widely used due to their simplicity and applicability (Li et al., 2006).

The mathematical expressions for the semi-empirical models are as follows:

$$
\begin{aligned}
& Q_{t}=K_{0} t+C_{0} \\
& Q_{t}=K_{H} \sqrt{t}+C_{H} \\
& Q_{t}=K_{R P} t^{n} \\
& Q_{t}=K_{1} t^{0.45}+K_{2} t^{0.90}
\end{aligned}
$$

where $Q_{t}$ is the cumulative percentage amount of drug released at time $t, Q_{0}$ is the initial amount of drug in gel, $K_{0}, K_{\mathrm{H},} K_{R P}, K_{1}, K_{2}$ are release rate constants, and $C_{0}, C_{H}$ are the respective y-intercepts in the absorbance vs. time curve. Ritger-Peppas and Peppas-Sahlin models were used specifically to explore release mechanisms and the fraction of drug release (due to diffusion), respectively. During the Ritger-Peppas model fitting, we obtained the value of the release exponent $n$, which conveys information on whether the release mechanism is Fickian, non-Fickian or case II transport mechanism. In this context, $n=0.5$ indicates Fickian release (diffusionally controlled release) 
and $n=1$ indicates a purely relaxation-controlled delivery, which is referred to as case II transport. When the value of $n$ is intermediate, it indicates an anomalous behavior (non-Fickian kinetics corresponding to coupled diffusion/ polymer relaxation). A value of $n>1$ indicates super case II kinetics. Based on the Peppas-Sahlin model, the fraction of drug release

$$
F=\frac{1}{1+\frac{K_{2}}{K_{1}} t^{0.45}}
$$

due to diffusion at a given instant of time $t$ can be calculated from (4) if $K_{1}$ and $K_{2}$ values are available.

Regarding statistical models, the underlying idea behind the use of statistical distribution in the modeling of drug release is to match the cumulative distribution function (CDF) of a particular distribution with the cumulative drug release; the underlying random variable (RV) being time $t$. CDF expressions in terms of RV are summarized as follows:

Weibull distribution: $Q_{t}=1-\exp \left(-\frac{t^{b_{W}}}{a_{W}}\right)$

Although linear fitting of log-transformed data is widely used, direct fitting was used here to avoid truncation or transformation errors. The goodness of fit was based on value of the regression coefficient $\left(r^{2}\right)$ and SSR.

\section{- Stability test}

For stability testing, the beads were kept at different temperature conditions, such as room temperature, $8 \pm 1^{\circ} \mathrm{C}$ (refrigerator temperature), and $30 \pm 2^{\circ} \mathrm{C}$ (condition for accelerated stability testing). Accelerated stability testing was performed at $75 \pm 5 \%$ relative humidity $(\mathrm{RH})$. The samples were withdrawn at different time intervals $(0,1$, and 3 months). Physical stability of the samples was determined by visual inspection. Chemical stability studies were carried out by measuring drug content and release profile.

\section{- Data and statistical analysis}

The steady-state release rate was calculated from the slope of the linear plot of the $\%$ cumulative drug released as a function of time ( $t$, hours).

Data are presented as mean \pm standard deviation (SD). Statistical comparisons were made using the Student $t$ test. The level of significance was set $p<0.05$. Data were analyzed using MS-excel software.

\section{RESULTS AND DISCUSSION}

\section{Particle size}

The spherical shape of alginate beads was obtained by using a Na-alginate concentration above $1.5 \%$. Beads are generally found to remain spherical even after drying. In this study, all beads prepared with $\mathrm{Na}$-alginate alone exhibited a spherical shape, and after addition of hydrophobic HPMC, no change was observed in their macroscopic features (Figures 1 and 2). Figures 1 and 2 clearly show that beads prepared with $\mathrm{Na}$-alginate alone and Na-alginate/hydrophobic HPMC were spherical in shape.

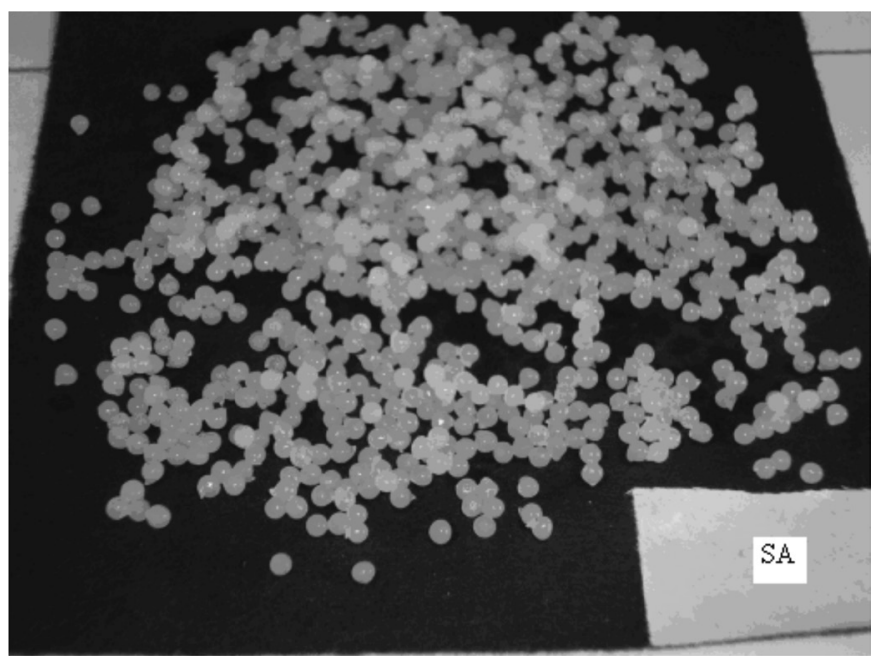

FIGURE 1 - Spherical shape of beads prepared with sodium alginate (SA) alone.

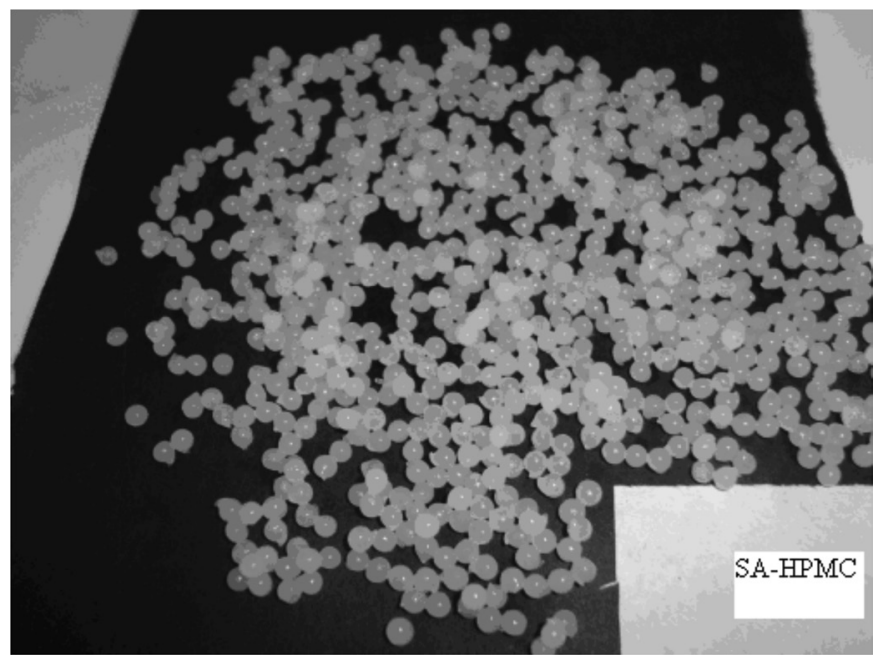

FIGURE 2- Spherical shape of beads prepared with sodium alginate (SA) and hydrophobic hydroxypropyl methylcellulose (HPMC). 
As described in Table II, the resulting beads were smaller, with ECD ranging from 3.24 to $4.04 \mathrm{~mm}$. There was no significant variation in particle size among the different formulations. The beads shrank upon drying, which generally occurs due to cross-linking of the polymer, and the drug entrapped within this cross-link is released in a retarded manner. Shape factors are generally used when studying a multiparticulate system. The beads, which are highly irregular in shape, exhibited large shape factor values, often ranging from 0.708 to 0.853 . These shape

TABLE I - Composition of different formulations used for preparation of diclofenac potassium microspheres

\begin{tabular}{|c|c|c|c|}
\hline Fn & $\begin{array}{l}\text { Sodium } \\
\text { alginate } \\
(\% \mathrm{w} / \mathrm{v})\end{array}$ & $\begin{array}{c}\text { Hydrophobic } \\
\text { HPMC } \\
(\% \text { w/v) }\end{array}$ & $\begin{array}{c}\text { Diclofenac } \\
\text { potassium } \\
(\% \mathrm{w} / \mathrm{v})\end{array}$ \\
\hline $\mathrm{S} 1$ & 2.00 & - & 2.00 \\
\hline S2 & 2.50 & - & 2.00 \\
\hline S3 & 3.00 & - & 2.00 \\
\hline A1 & 2.00 & 0.20 & 2.00 \\
\hline A2 & 2.00 & 0.50 & 2.00 \\
\hline A3 & 2.00 & 0.80 & 2.00 \\
\hline B1 & 2.50 & 0.20 & 2.00 \\
\hline B2 & 2.50 & 0.50 & 2.00 \\
\hline B3 & 2.50 & 0.80 & 2.00 \\
\hline $\mathrm{C} 1$ & 3.00 & 0.20 & 2.00 \\
\hline $\mathrm{C} 2$ & 3.00 & 0.50 & 2.00 \\
\hline C3 & 3.00 & 0.80 & 2.00 \\
\hline
\end{tabular}

$\mathrm{Fn}=$ formulation, $\mathrm{HPMC}=$ hydroxypropyl methylcellulose . factor values show that the beads achieved a spherical shape. Area and perimeter were within 9.07-12.81 $\mathrm{mm}^{2}$ and $9.00-10.90 \mathrm{~mm}$, respectively. An average of six readings was recorded (mean $\pm \mathrm{SD}$ ).

\section{Entrapment efficiency}

Entrapment efficiency is an important parameter for beads and generally depends on curing time in the coagulation fluid (calcium chloride solution). The drug can diffuse into the fluid, and higher curing time means higher drug diffusion into the fluid. As a result, the amount of drug entrapped in the beads decreases. In this study, curing time (30 $\mathrm{min}$ ) was the same for all beads, and the average amount of drug entrapped in the beads was about $78-87 \%$ (Table III). An average of six readings was recorded (mean $\pm \mathrm{SD}$ ).

\section{Swelling capacity}

The swelling profile of hydrophobic HPMC/Na-alginate beads and beads with $\mathrm{Na}$-alginate alone in distilled water is shown in Table IV. When phosphate buffer is used, the swelling rate of beads cannot be estimated because of very quick erosion. When immersed in distilled water, Na-alginate beads immediately begin to swell, recovering their initial spherical shape. On the other hand, crosslinked hydrophobic HPMC/Na-alginate beads initially exhibit a more rapid diameter increase, which slows down after $15 \mathrm{~min}$, while keeping their shape. Water uptake increases with time, leading to an initial loss of spherical shape within 3 hours. The swelling rate of beads tended to decrease as the concentration of hydrophobic HPMC

TABLE II - Shape parameters of the different formulations

\begin{tabular}{lccccc}
\hline Formulation & Area $\left(\mathrm{mm}^{2}\right)$ & Perimeter $(\mathrm{mm})$ & Shape & Shape factor & ECD $(\mathrm{mm})$ \\
\hline S1 & $9.07 \pm 0.01$ & $9.82 \pm 0.09$ & spherical & $0.846 \pm 0.12$ & $3.40 \pm 0.11$ \\
S2 & $9.33 \pm 0.02$ & $10.00 \pm 0.16$ & spherical & $0.853 \pm 0.11$ & $3.45 \pm 0.16$ \\
S3 & $8.23 \pm 0.03$ & $9.00 \pm 0.21$ & spherical & $0.783 \pm 0.14$ & $3.24 \pm 0.12$ \\
A1 & $12.62 \pm 0.01$ & $11.02 \pm 0.11$ & spherical & $0.708 \pm 0.12$ & $4.01 \pm 0.22$ \\
A2 & $10.39 \pm 0.02$ & $10.10 \pm 0.19$ & spherical & $0.782 \pm 0.21$ & $3.64 \pm 0.18$ \\
A3 & $12.52 \pm 0.01$ & $11.00 \pm 0.21$ & spherical & $0.769 \pm 0.19$ & $4.00 \pm 0.08$ \\
B1 & $9.33 \pm 0.02$ & $10.01 \pm 0.15$ & spherical & $0.855 \pm 0.16$ & $3.45 \pm 0.10$ \\
B2 & $12.69 \pm 0.11$ & $11.00 \pm 0.12$ & spherical & $0.759 \pm 0.17$ & $4.02 \pm 0.12$ \\
B3 & $12.81 \pm 0.09$ & $11.05 \pm 0.22$ & spherical & $0.759 \pm 0.18$ & $4.04 \pm 0.11$ \\
C1 & $12.50 \pm 0.10$ & $10.90 \pm 0.119$ & spherical & $0.757 \pm 0.19$ & $3.99 \pm 0.20$ \\
C2 & $9.07 \pm 0.07$ & $9.65 \pm 0.21$ & spherical & $0.817 \pm 0.16$ & $3.40 \pm 0.12$ \\
C3 & $9.89 \pm 0.03$ & $9.69 \pm 0.09$ & spherical & $0.756 \pm 0.15$ & $3.55 \pm 0.17$ \\
\hline
\end{tabular}

$\mathrm{ECD}=$ equivalent circular diameter. 
TABLE III -Entrapment efficiency of microspheres

\begin{tabular}{lc}
\hline Fn & $\begin{array}{c}\text { Entrapment efficiency }(\% \mathrm{w} / \mathrm{w}) \\
(\text { Mean } \pm \text { SD) }\end{array}$ \\
\hline S1 & $87.44 \pm 2.50$ \\
S2 & $81.74 \pm 1.11$ \\
S3 & $83.88 \pm 1.23$ \\
A1 & $85.55 \pm 2.01$ \\
A2 & $82.54 \pm 1.21$ \\
A3 & $87.55 \pm 1.41$ \\
B1 & $83.76 \pm 2.01$ \\
B2 & $77.89 \pm 2.03$ \\
B3 & $79.65 \pm 1.43$ \\
C1 & $82.48 \pm 1.23$ \\
C2 & $80.90 \pm 1.65$ \\
C3 & $81.32 \pm 1.77$ \\
\hline
\end{tabular}

$\mathrm{Fn}=$ formulation; $\mathrm{SD}=$ standard deviation.

increased due to strong interaction between two oppositely charged polymers. Incorporation of hydrophobic HPMC prolonged the swelling properties of beads, because hydrophobic HPMC provided higher viscosity levels than $\mathrm{Na}$-alginate, thus preventing a quick loss of the initial spherical shape. The swelling rate of beads was obtained from the slope of the relationship between \% swelling capacity and time. This relationship provided good linearity $\left(r^{2}>0.98\right)$ when assessed by linear regression analysis (Table IV). In this study, we compared swelling capacity between Na-alginate beads (S1) and Na-alginate/hydrophobic HPMC beads (from A1 to A3). Average swelling capacity of six beads was shown (mean \pm SD). The swelling rate of Na-alginate beads is 19.32 , and as the polymer content in formulation increases ( $\mathrm{S} 3>\mathrm{S} 2>\mathrm{S} 1)$, the swelling rate decreases $(10.09<15.01<18.56)$. The presence of hydrophobic HPMC in the beads maintained swelling for a longer time than Na-alginate alone.

TABLE IV - Swelling characteristics of sodium alginate (Naalginate) beads and hydrophobic hydroxypropyl methylcellulose (HPMC)/Na-alginate beads

\begin{tabular}{lcc}
\hline Fn & $\begin{array}{c}\text { Swelling rate } \\
(\text { Mean } \pm \text { SD })\end{array}$ & $\begin{array}{c}\text { Regression } \\
\text { coefficient }\left(\mathrm{r}^{2}\right)\end{array}$ \\
\hline $\mathrm{S} 1$ & $19.32 \pm 0.01$ & 0.9804 \\
$\mathrm{~A} 1$ & $18.56 \pm 0.01$ & 0.9901 \\
$\mathrm{~A} 2$ & $15.01 \pm 0.03$ & 0.9802 \\
$\mathrm{~A} 3$ & $10.09 \pm 0.02$ & 0.99921 \\
\hline
\end{tabular}

$\mathrm{Fn}=$ formulation, $\mathrm{SD}=$ standard deviation.

\section{Erosion studies}

Results are plotted in Figure 3. In erosion tests run in phosphate buffer ( $\mathrm{pH}$ 7.4), both types of beads exhibited an initial increase in volume. Na-alginate beads started to erode significantly at 30-45 min, losing their spherical shape after 120-180 min, whereas the crosslinked formulations kept their shape throughout the test (50\% integrity after 4 hours). This feature was also observed throughout the drug release tests and is probably the main cause underlying the prolonged release of the drug from the beads.

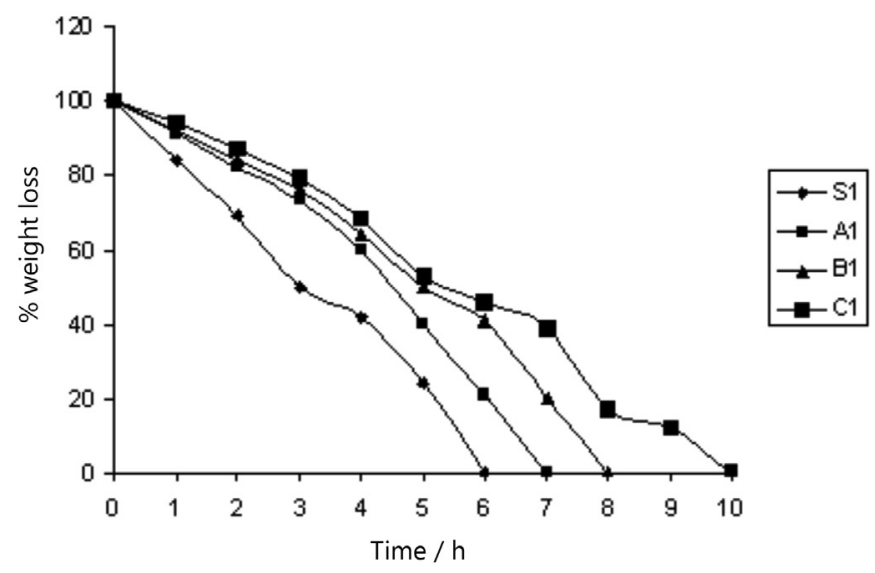

FIGURE 3 - \% weight loss of different hydrogel beads due to erosion.

\section{Release tests}

Drug release profiles of beads are shown in Figures $4,5,6$, and 7. Alginate is insoluble in acidic $\mathrm{pH}$. At low $\mathrm{pH}$, the number of positively charged ions is high, and they reduce the electrical repulsion between the negatively charged alginate molecules (Gonzalez-Rodriguez et al., 2002). Alginate is protonated into the insoluble form of alginic acid. Thus, penetration of dissolution fluid through the polymer is hindered, and the percentage of drug released due to diffusion through the polymer network was minimal at $\mathrm{pH} 1.2$ for all beads. Initial drug release (up to $12 \%$ ) may be attributed to the leaching of the drug on the bead outer surface. When $\mathrm{pH}$ is increased, drug release increases up to $100 \%$. Deprotonation of alginic acid occurs at higher $\mathrm{pH}$ values. It will draw fluid into the beads, which swell and burst apart. Thus, drug release rate increases at basic $\mathrm{pH}$. Three types of hydrogel beads were formulated using 2.0, 2.5 and $3.0 \% \mathrm{w} / \mathrm{v}$ concentrations of $\mathrm{Na}$-alginate alone. All beads released the drug within 6 hours. As the polymer concentration increased, diffusional resistance to drug release also in- 


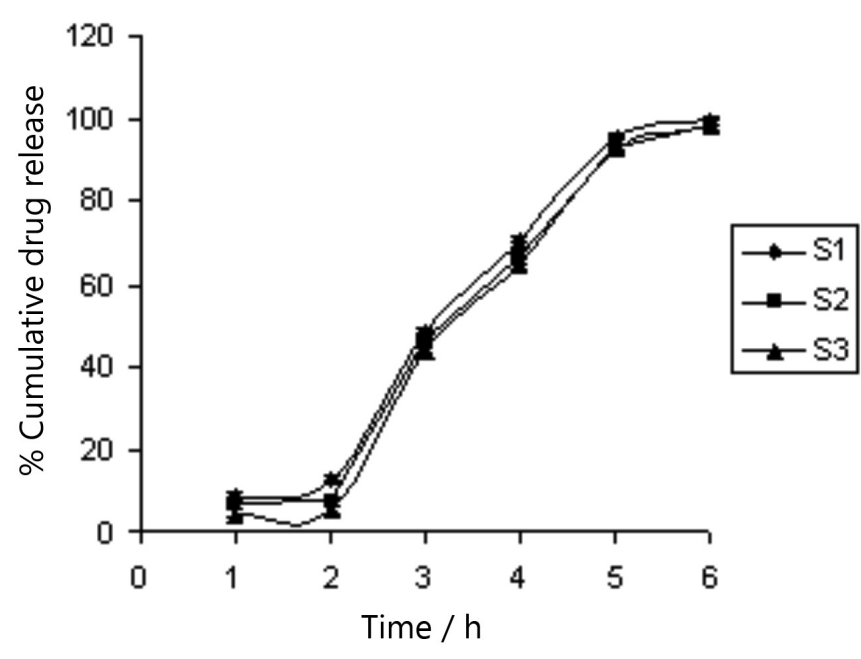

FIGURE 4 - Comparative results of in vitro release profile of hydroxypropyl methylcellulose (HPMC) with sodium alginate (SA)-based diclofenac beads.

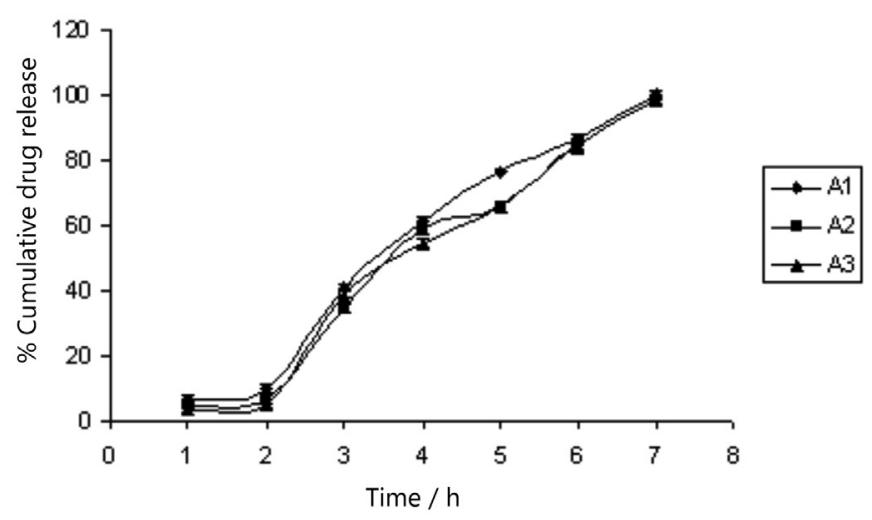

FIGURE 5 - Comparative results of in vitro release profile of hydroxypropyl methylcellulose (HPMC) with sodium alginate (SA)-based diclofenac beads.

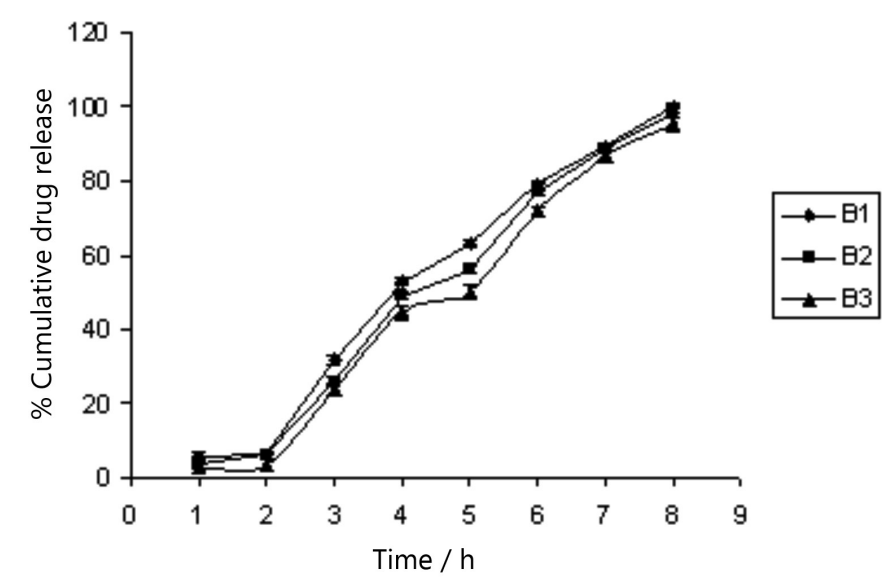

FIGURE 6 - Comparative results of in vitro release profile of hydroxypropyl methylcellulose (HPMC) with sodium alginate (SA)-based diclofenac beads.

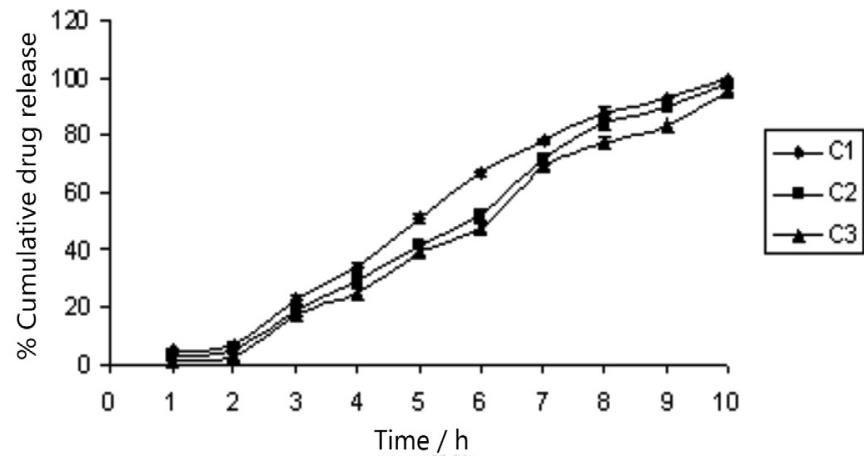

FIGURE 7 - Plot of \% cumulative drug release vs. time (in hours). Data expressed as mean \pm standard deviation $(\mathrm{n}=6)$.

creased, which, in turn, decreased drug release. It is clear that as the polymer content in the formulation increases $(\mathrm{S} 3>\mathrm{S} 2>\mathrm{S} 1), \%$ cumulative drug release at a 6-hour interval $(98.57<98.67<99.69)$ decreases.

Combination of alginate and hydrophobic HPMC produced a sustained effect on drug release in the formulations. Conventional HPMC was combined with a small amount of a long-chain alkyl group to obtain HPMC stearoxy ether. This modified hydrophobic HPMC has a higher positive charge due to the presence of a longchain alkyl group. Na-alginate is a polyanionic polymer. Carboxylate groups are present on the Na-alginate chain. Positively charged groups of hydrophobic HPMC strongly interact with alginate and diclofenac ions, thus reducing both swelling and release - probably due to protonation of carboxylated groups from $\mathrm{Na}$-alginate.

In this study, different combinations of alginate and hydrophobic HPMC beads were prepared. Na-alginate concentration was fixed at 2.0, 2.5 and $3.0 \% \mathrm{w} / \mathrm{v}$, and 0.2 , 0.5 and $0.8 \%$ hydrophobic HPMC were added to prepare A1 to $\mathrm{C} 3$ formulations (total of 9 formulations). Addition of hydrophobic HPMC was shown to sustain drug release for a longer period of time (for A1, A2 and A3, 7 hours; for B1, B2, B3, 8 hours; and for C1, C2 and C3, 10 hours). The alginate/hydrophobic HPMC combination provided an alternative system for controlling the release of DP in bead form. This study also showed, as observed in Figures 5,6 , and 7 , that as the polymer content in the combined formulation increases, $\%$ cumulative drug release at a 6-hour interval decreases. Although the amount of hydrophobic HPMC used $(0.2,0.5$, and $0.8 \% \mathrm{w} / \mathrm{v})$ is very low, it can retard drug release for a long period of time. High viscosity was obtained due to the hydrophobic interaction of the long-chain alkyl group, and based on Fick's law of diffusion, it may be inferred that as the viscosity of the formulation increases, molecular diffusivity (diffusion coefficient) and $\%$ release also decrease. 


\section{Release kinetics study}

As observed in Table V, the correlation coefficient $\left(r^{2}\right)$ and SSR for zero-order ranged from 0.9527 to 0.9876 and from 141.28 to 384.53 , respectively, demonstrating that drug release follows zero-order kinetics. The correlation coefficient and SSR for Higuchi equation ranged from 0.9262 to 0.9671 and from 287.93 to 544.82 , respectively; however, it was not possible to conclude that drug release is totally based on diffusion. In order to obtain a clearer view of the release process, the Ritger-Peppas model was used. Table VI shows that the highest $r^{2}$ values (ranging from 0.9393 to 0.9834 ) and lowest SSR values (ranging from 176.08 to 518.69 ) were obtained from this model, meaning that the best release pattern can be analyzed by this model. This model yielded $n$ values that were higher than 1, which may be regarded as super case II kinetics arising from a reduction in the attractive forces between polymer chains. In this study, drug release was dependent on the relaxation rate of polymer chains. At higher $\mathrm{pH}$, deprotonation of alginic acid weakens the extent of interaction, and polymers within the microsphere are found in the relaxed form. Addition of hydrophobic HPMC leads to a greater retarded release due to increased concentra- tion and viscosity. According to the Peppas-Sahlin model, a negative value of $K_{1}$ was obtained (Table V), which can be reported as an insignificant effect of Fickian diffusion on drug release compared to the relaxation process.

The Weibull distribution cannot describe drug release kinetics, but it can describe the curve in terms of applicable parameters. As the value for shape parameter $(\beta)$ was higher than 1 , plots should be "S" shaped with an upward curvature. The values for $\beta, r^{2}$, SSR and $a$ are described in Table V. The Weibull distribution gave a good fit for the data when explaining in vitro release profile, as $r^{2}$ (0.9766- 0.9906) had the highest and SSR (0.0024-0.0191) the lowest values.

\section{STABILITY STUDY}

Stability testing was performed at different temperatures and conditions. However, no significant reduction was observed in the percentage of drug retained in the formulations. Likewise, there was no significant difference in drug release profile between samples stored at $2-8^{\circ} \mathrm{C}$ and at room temperature. Because DP is a light-sensitive drug, it was suggested that formulations should be protected from light.

TABLE V - Parameter and correlation coefficients for zero-order equation, Higuchi equation, and Weibull distribution

\begin{tabular}{|c|c|c|c|c|c|c|c|c|c|c|c|c|}
\hline \multirow[t]{2}{*}{ Fn } & \multicolumn{4}{|c|}{ Zero-order: $Q=K_{o}+C$} & \multicolumn{4}{|c|}{ Higuchi: $Q=K_{H} t^{0.5}+C$} & \multicolumn{4}{|c|}{$\begin{array}{c}\text { Weibull distribution: } \\
\log [\ln (1 / 1-m)]=\beta \log (t)-\log (a) .\end{array}$} \\
\hline & $K_{0}$ & $C$ & $r^{2}$ & SSR & $K_{H}$ & $C$ & $r^{2}$ & SSR & $a$ & $\beta$ & $r^{2}$ & SSR \\
\hline $\mathrm{S} 1$ & 20.74 & -16.83 & 0.9574 & 334.94 & 71.68 & -73.63 & .9332 & 438.62 & 42.18 & 2.92 & 0.9879 & 0.0096 \\
\hline S2 & .0 & -20.46 & 0.9527 & 384.53 & 72.55 & -77.76 & 0.9348 & 530.40 & 55.31 & 3.05 & 0.9841 & 0.0129 \\
\hline S3 & 21.60 & -24.05 & 0.9558 & 377.98 & 74.40 & -82.76 & 0.9262 & 544.82 & 73.70 & 3.22 & 0.9865 & 0.0115 \\
\hline A1 & 16.78 & -12.67 & 0.9713 & 232.77 & 61.88 & -64.67 & 0.9568 & 269.52 & 28.37 & 2.34 & 0.9882 & 0.0096 \\
\hline $\mathrm{A} 2$ & 16.79 & -16.54 & 0.9746 & 206.12 & 61.50 & -67.78 & 0.9573 & 346.07 & 36.56 & 2.39 & 0.9804 & 0.0158 \\
\hline A3 & 16.85 & -17.41 & 0.9756 & 199.23 & 61.79 & -68.98 & 0.9509 & 318.94 & 35.70 & 2.36 & 0.9766 & 0.0191 \\
\hline B1 & 14.43 & -11.18 & 0.9820 & 160.77 & 56.01 & -60.39 & 0.9633 & 287.93 & 31.66 & 2.20 & 0.9906 & 0.0084 \\
\hline B2 & 14.72 & -15.70 & 0.9828 & 159.74 & 56.77 & -65.16 & 0.9517 & 354.92 & 49.66 & 2.40 & 0.9889 & 0.0103 \\
\hline B3 & 14.72 & -18.6 & 0.9 & 161. & 56.4 & -67.40 & 0.9 & 46 & 67.94 & 2.51 & 0.9842 & 0.0147 \\
\hline $\mathrm{C} 1$ & 11.43 & -9.11 & 0.9712 & 320.29 & 48.75 & -55.77 & 0.9671 & 364.83 & 49.88 & 2.22 & 0.9979 & 0.0024 \\
\hline $\mathrm{C} 2$ & 11.70 & -15.02 & 0.9876 & 141.49 & 49.15 & -61.13 & 0.9552 & 511.82 & 94.26 & 2.45 & 0.9940 & 0.0069 \\
\hline $\mathrm{C} 3$ & 11.27 & -15.74 & 0.9867 & 141.28 & 47.27 & -59.96 & 0.9505 & 526.01 & 94.25 & 2.38 & 0.9895 & 0.0111 \\
\hline
\end{tabular}

$\mathrm{Fn}=$ formulation, $\mathrm{Q}=\%$ cumulative amount of release, $\mathrm{t}=$ time in hours, $K_{0}=$ zero-order constant, $\mathrm{C}=$ intercept, $K_{H}=\mathrm{Higuchi}$ constant, $\mathrm{m}=$ accumulated fraction of the drug; $\beta=$ shape parameter; $\mathrm{a}=$ scale parameter, $\mathrm{r}^{2}=$ regression coefficient, $\mathrm{SSR}=$ sum of squared residuals. 
TABLE VI - Parameter and correlation coefficients for Ritger-Peppas and Peppas-Sahlin models

\begin{tabular}{lcccccccc}
\hline \multirow{2}{*}{ Fn } & \multicolumn{3}{c}{ Ritger-Peppas: $\boldsymbol{Q}=\boldsymbol{K}_{\boldsymbol{R P}} \boldsymbol{t}^{\boldsymbol{n}}$} & \multicolumn{4}{c}{ Peppas-Sahlin: $\boldsymbol{Q}=\boldsymbol{K}_{\mathbf{1}} \boldsymbol{t}^{\mathbf{0 . 4 5}}+\mathbf{K}_{\mathbf{2}} \boldsymbol{t}^{\mathbf{0 . 9 0}}$} \\
\cline { 2 - 8 } & $K_{R P}$ & $r^{2}$ & $n$ & SSR & $K_{1}$ & $K_{2}$ & $r^{2}$ & SSR \\
\hline S1 & 10.58 & 0.9467 & 1.30 & 418.80 & -29.97 & 34.94 & 0.9578 & 331.57 \\
S2 & 8.84 & 0.9402 & 1.40 & 486.94 & -35.02 & 36.90 & 0.9538 & 375.75 \\
S3 & 7.64 & 0.9393 & 1.48 & 518.69 & -39.93 & 39.09 & 0.9571 & 366.60 \\
A1 & 10.06 & 0.9601 & 1.20 & 224.30 & -22.12 & 27.43 & 0.9708 & 237.36 \\
A2 & 7.59 & 0.9638 & 1.34 & 203.37 & -27.49 & 29.09 & 0.9748 & 203.79 \\
A3 & 7.33 & 0.9624 & 1.35 & 306.54 & -28.40 & 29.40 & 0.9752 & 201.72 \\
B1 & 8.82 & 0.9729 & 1.19 & 241.05 & -19.22 & 23.61 & 0.9817 & 163.43 \\
B2 & 6.58 & 0.9733 & 1.33 & 247.60 & -25.21 & 25.71 & 0.9834 & 154.23 \\
B3 & 4.96 & 0.9773 & 1.46 & 210.33 & -29.19 & 26.88 & 0.9852 & 137.20 \\
C1 & 7.82 & 0.9720 & 1.13 & 422.09 & -14.94 & 18.53 & 0.9711 & 320.60 \\
C2 & 4.69 & 0.9826 & 1.35 & 198.36 & -22.68 & 21.00 & 0.9885 & 120.42 \\
C3 & 3.93 & 0.9834 & 1.41 & 176.08 & -23.37 & 20.64 & 0.9892 & 115.07 \\
\hline
\end{tabular}

Fn = formulation, $K_{R P}=$ Ritger-Peppas constant, $K_{l}, K_{2}=$ Peppas-Sahlin constant, $r^{2}=$ regression coefficient, $\mathrm{SSR}=$ sum of squared residuals.

\section{CONCLUSION}

A new matrix using Na-alginate and hydrophobic HPMC was prepared and used in the controlled release of diclofenac. We demonstrated that it is possible to prepare diclofenac-loaded beads with high encapsulation efficiency and high swelling capacity. The method developed is simple, fast and reproducible. A remarkable delay in the release of diclofenac was observed for $\mathrm{Na}$-alginate HPMC beads. This matrix also offered a degree of protection against premature drug release in simulated upper GI transit conditions. Matrix swelling induced by phosphate buffer did not lead to complete destruction of $\mathrm{Na}$-alginate HPMC beads, which results in prolonged retention of the drug within the polymer matrix.

\section{ACKNOWLEDGEMENTS}

The authors wish to thank Daido Chemical Corporation and Kontest Chemicals, Kolkata, India, for providing hydrophobic HPMC and DP, respectively, as gift samples. We also offer sincere thanks to Mr. Aniruddha Chandra, Mrs. Nita Mondal and other colleagues for their different kinds of help during research studies.

\section{REFERENCES}

ACIKGOZ, M.; KAS, H.S.; HASCELIK, Z.; MILLI, U.; HINCAL, A.A. Chitosan microspheres of diclofenac sodium, II: in vitro and in vivo evaluation. Pharmazie, v.50, p.275-277, 1995.
BELYAEVA, E.; VALLE, D.D.; NEUFELD, R.J.; PONCELET, D. New approach to the formulation of hydrogel beads by emulsification/thermal gelation using a static mixer. Chem Eng. Sci., v.59, p.2913-2920, 2004.

BENNETT, N.; PAPICH, M.G.; HOENIG, M.; FETTMAN, M.J.; LAPPIN, M.R. Evaluation of transdermal application of glipizide in a pluronic lecithin gel to healthy cats. Am. $J$. Vet. Sci., v.66, p.581-588, 2005.

DAS, M.K.; AHMED, A.B. Formulation and ex vivo evaluation of rofecoxib gel for topical application. Acta Pol. Pharm., v.64, p.461-467, 2007.

EBUBE, N.K., HIKAL, A.H.; WYANDT, C.M.; BEER, D.C; MILLER, L.G.; JONES, A.B. Sustained release of acetaminophen from heterogeneous matrix tablets: influence of polymer ratio, polymer loading, and co- active on drug release. Pharm. Dev. Technol., v.2, p.161-170, 1997.

ESCRIBANOA, E.; CALPENA, A.C.; QUERALT, J.; OBACHA, R.; DOMENECHA, J. Assessment of diclofenac permeation with different formulations: anti-inflammatory study of a selected formula. Eur. J. Pharm. Sci., v.9, p.203210, 2003.

FERNANDEZ-HERVAS, M.J.; HOLGADO, M.A.; FINI, A.; FELL, J.T. In vitro evaluation of alginate beads of a diclofenac salt. Int. J. Pharm., v.163, p.23-34, 1998. 
FERREIRA-ALMEIDA, P.; ALMEIDA, A.J.; Cross-linked alginate-gelatine beads: a new matrix for controlled release of pindolol. J. Control. Release, v.97, p.431-439, 2004.

GACESA, P. Alginate. Carbohydr. Polym., v.8, p.161-182, 1988.

GANESH, S.; RADHAKRISHNAN, M.; RAVI, M.; PRASANNAKUMAR, B.; KALYANI, J. In vitro Evaluation of the Effect of Combination of Hydrophilic and Hydrophobic Polymers on Controlled Release from Zidovudine Matrix Tablets. Indian J. Pharm. Sci., v.70, p.461-465, 2008.

GHOSAL, K.; RAJABALAYA, R.; CHAKRABORTY, S.; NANDA, A. Formulation and Characterization of both Hydrophilic and Hydrophobic HPMC based Hydrogels containing Diclofenac Potassium. Latin Am. J. Pharm., v.29, p.1137-1143, 2010.

GONZALEZ-RODRIGUEZ, M.L.; HOLGADO, M.A.; SANCHEZ-LAFUENTE, C.; RABASCO, A.M.; FINI, A. Alginate/chitosan particulate systems for sodium diclofenac release. Int. J. Pharm., v.232, p.225-234, 2002.

GURSOY, A.; CEVIK, S. Sustained release properties of alginate microspheres and tabletted microspheres of Diclofenac sodium. J. Microencapsul., v.17, p.565-575, 2000 .

JAIN, S.K.; JAIN, A.; GUPTA, Y.; AHIRWAR, M. Design and development of hydrogel beads for targeted drug delivery to the colon. AAPS PharmSciTech., v.8, p.E1-E8, 2007.

KULKARNI, A.R.; SOPPIMATH, K.S.; AMINABHAVI, T.M.; RUDZINSKI, W.E. In vitro release kinetics of cefadroxil, loaded sodium alginate interpenetrating network beads. Eur. J. Pharm. Biopharm., v.51, p.127-133, 2001.

LETICIA, S.K., ORTEGA, G.G.; MAYORGA, P.; BASSANI, V.L. Mathematical evaluation of in vitro release profiles of hydroxypropylmethylcellulose matrix tablets containing carbamazepine associated to b-cyclodextrin. Eur. J. Pharm. Biopharm., v.58, p.177-179, 2004.

LI, S.; SHEN, Y.; LI, W.; HAO, X.A. common profile for polymer-based controlled release and its logical interpretation to general release process. J. Pharm. Pharm. Sci., v.9, p.238-244, 2006.
LIN, S.Y.; KAO, Y.H. Tablet formulation study of spray-dried sodium diclofenac enteric-coated microcapsules. Pharm. Res., v.8, p.919-924, 1991.

LIN, S.Y.; AYRES, J.W. Calcium alginate beads as core carriers of 5-aminosalcylic acid. Pharm. Res., v.9, p.11281131,1992 .

ØSTBERG, T.; LUND, E.M.; GRAFFNER, C. Calcium alginate matrices for oral multiple unit administration: IV. Release charateristics in different media. Int. J. Pharm., v.112, p.241-248, 1994.

PEPPAS, N.A.; SAHLIN, J.A. A simple equation for the description of solute release III. Coupling of diffusion and relaxation. Int. J. Pharm., v.57, p.169-172, 1989.

RAO, R.K.V.; PADMALATHA DEVI, K.; BURI, P. Cellulose matrices for zero-order release of soluble drugs. Drug Dev. Ind. Pharm., v.14, p.2299-2320, 1988.

SABNIS, S.; REGE, P.; BLOCK, L.H. Use of chitosan in compressed tablets of diclofenac sodium: inhibition of drug release in an acidic environment. Pharm. Dev. Technol., v.2, p.243-255, 1997.

SANNA, V.; PEANA, A.T.; MORETTI, M.D.L. Effect of vehicle on diclofenac sodium permeation from new topical formulations: in vitro and in vivo studies. Curr. Drug Dev., v.6, p.93-100, 2009.

SHU, X.J.; ZHU, K.J. The release behavior of brilliant blue from calcium-alginate gel beads coated by chitosan: the preparation method effect. Eur. J. Pharm. Sci., v.53, p.193$201,2002$.

SINHA, D.R.; ROHERA, B.D. Comparative evaluation of rate of hydration and matrix erosion of HEC and HPC and study of drug release from their matrices. Eur. J. Pharm. Sci., v.16, p.193-199, 2002.

SINTOV, A.C.; BOTNER, S. Transdermal drug delivery using microemulsion and aqueous systems: Influence of skin storage conditions on the in vitro permeability of diclofenac from aqueous vehicle systems. Int. J. Pharm., v.311, p.55$62,2006$.

SMIDSRD, O.; SKJAK-BRÆK, G. Alginate as immobilization matrix for cells, Trends. Biotechnol., v.8, p.71-78, 1990. 
SRIAMORNSAK, P.; THIRAWONG, N.; PUTKHACHORN, S. Morphology and buoyancy of entrapped calcium pectinate gel beads. AAPS J., v.6, p.1-7, 2004.

SRINATHA, A.; PANDIT, J.K.; SINGHA, S. Ionic cross-linked chitosan beads for extended release of ciprofloxacin: in vitro characterization. Indian J. Pharm. Sci., v.70, p.16-21, 2008.
YOTSUYANAGI, T.; YOSHIOKA, I.; SEGI, N.; IKEDA, K. Acid-induced and calcium-induced gelation of alginic acid: Bead formation and $\mathrm{pH}$ dependent swelling. Chem. Pharm. Bull., v.39, p.1072-1074, 1991.

Received for publication on $07^{\text {th }}$ September 2010 Accepted for publication on $07^{\text {th }}$ June 2011 